\title{
Razón de amor como una broma secreta
}

\author{
Reason for love as a secret joke
}

Daniel Salas Díaz

CENTRUM Católica, Lima, Perú. Correo electrónico: dsalasd@ pucp.edu.pe

Desde el descubrimiento del manuscrito del poema conocido como Razón de amor, la pregunta por la unidad de las dos partes que componen el texto ha intrigado a los críticos. En este artículo propongo que la coherencia del texto no se encuentra en la relación entre los temas sino en el propósito humorístico de los versos. Sostengo que Razón de amor es una broma que aborda las angustias sexuales y espirituales de los clérigos aragoneses que lo leían y que su condición de objeto destinado a provocar la risa explica la incongruencia temática de esta famosa pieza poética.

Palabras clave: Razón de amor, broma, masculinidad.

Ever since the manuscript of the poem known as Razon de amor was found, the problem of the unity of its two parts has puzzled the critics. In this article I propose that the coherence of the text is not to be found in the relationship between the topics but in the humoristic purposes of the verses. I hold that Razón de amor is a joke that deals with the sexual and spiritual anxieties of the Aragonese clerics who read it and that its condition of an object designed to provoke laughter explains the thematic inconsistencies of this famous piece of poetry.

Key words: Razón de amor, joke, masculinity.

El poema castellano-aragonés conocido como Razón de amor $(=R d A)$ debe ser uno de los textos peninsulares sobre los cuales hay más consenso crítico en torno a su rareza y naturaleza enigmática ${ }^{1}$. Ya en 1902, unos años después de la primera publicación en 1887 por Alfred Morel-Fatio, Carolina Michaelis de Vasconcelos lo describía de esta manera:

Curioso como documento archaïco e pelo artístico, é-o muito mais por duas particularidades: $1^{\circ}$. Quanto á fórma, por certos cambiantes dialectaes da linguagem que caracterizam o clerigo que o ideou, ou o copista cujo treslado possuimos, como aragonês, na opinião quase consentánea dos críticos. $2^{\circ}$. Quanto ao assumpto, pelo pelegrino ou cerebrino enlace de dois themas completamente diversos e desconexos, sendo um, predilecto dos trovadores aristocratas de Occidente, e o outro, um thema vulgar e internacional da poesia profana de goliardos e jograres" (Michaelis de Vasconcelos 1902: 1-2).

\footnotetext{
${ }^{1}$ Las referencias al poema están tomadas de la edición de Enzo Franchini (Los debates literarios).
} 
Desde el descubrimiento moderno del manuscrito, la impresión que el poema posee una naturaleza inaprensible ha sido un motivo muy frecuentado por la crítica.

En su artículo de 1968, Daniel N. Cárdenas sostiene que "[e]l lector avisado, al leer este poema, se da cuenta de una cualidad artística indefinible" (Cárdenas 1968: 228). Para Ramón Menéndez Pidal, en su edición del poema publicada en una colección de textos medievales en 1976, las inconsistencias de $R d A$ dan señales de que el poeta era "muy distraído" (Menéndez Pidal 1976: 106). En su estudio de 1978, Margaret Van Antwerp comienza su análisis sosteniendo que "pocos trabajos del Medioevo español han llamado más la atención que el problemático Razón de amor con los denuestos del agua y del vino" (Antwerp 1978: 1) 2. En un trabajo publicado en 1979, Olga Tudorica Impey, después de referirse a la segunda parte del poema como "un dúo grosero y discorde", argumenta que "[e]l acoplamiento disonante de estos dos dúos o diálogos así como el de géneros completamente distintos ha intrigado y sigue intrigando a los críticos" (Tudorica Impey 1979: 2). Por su parte, María Cristina Azuela, en un artículo publicado en 1993, sostiene que se trata de un texto en el cual el poeta "se oculta bajo las distintas voces narrativas en un juego de espejos que parecería tener como fin único la desorientación del lector" (Azuela 1993: 201).

Concedamos por un momento que $R d A$ es un poema confuso debido a la diversidad y contrariedad de elementos y géneros que reúne. Preguntémonos, entonces, si es posible hallar algún género capaz de abordar los otros y dar coherencia a dicha disparidad. La respuesta que ofrezco es que sí lo es, pero a condición de que no lo busquemos en la historia de la lírica castellana, sino en la práctica cotidiana, ya que ese género que le da consistencia al texto no es un modelo literario, sino un tipo de enunciado: el chiste.

Mi respuesta no debería sorprender. A medida que avanzamos en la historia de la crítica sobre $R d A$, se hace cada vez más notorio que el poema tiene mucho que ver con el humor. En su libro de 2001, Enzo Franchini señala, por un lado, que $R d A$ "es insólita en todos sus aspectos, tanto en lo que a la transmisión manuscrita como a su fisonomía dialectal y a su valor literario se refiere" (Franchini 2001: 43). Páginas más adelante agrega un comentario que resulta siendo el más novedoso y crucial: a su juicio, el poema es “una obra compuesta por 'un tío muy listo', deseoso de lucirse con su incontestable erudición y sus amplios conocimientos literarios" (Franchini 2001: 63). Posteriormente concluye que se trata de "[1]a representación pícara y autoirónica de un problema hondamente humano" (Franchini 2001: 79). Este problema "hondamente humano", no es otro que la consumación del acto sexual.

Mi propósito es ofrecer una interpretación de $R d A$ basándome en conclusiones derivadas del escrupuloso escrutinio del manuscrito realizado por Enzo Franchini. Como espero demostrar, la pregunta en torno a la singularidad de este poema, y especialmente en lo que respecta a su coherencia y unidad, se resuelve de manera convincente y sencilla reinscribiendo el texto dentro de su contexto manuscrito y como objeto mediador de un tipo de enunciación que es la broma o el chiste.

Mi aproximación es, pues, performativa. Ella considera que el objeto de análisis crítico es un instrumento destinado a mediar en la representación del sujeto y el mundo. De acuerdo con Richard Bauman y Charles L. Briggs, el estudio de la performance

2 "[f]ew works of the Spanish Middle Ages have attracted more critical attention than the problematic Razón de amor con los denuestos del agua y del vino" (Antwerp 1978: 1). 
abre una nueva perspectiva de los análisis del texto ya que "proporciona un marco que invita a la reflexión crítica sobre los procesos comunicativos" (Bauman y Briggs 1990: 60) ${ }^{3}$. Ellos sostienen que:

Los académicos orientados al tema de la performance ya no consideran que la performatividad sea, principalmente, el uso de rasgos específicos que señalen efectos ilocucionarios particulares dentro de un conjunto de convenciones fijas y en un contexto social dado. En cambio, la ven como una interacción de patrones formales complejos y heterogéneos en la construcción social de la realidad ${ }^{4}$.

Este tipo de análisis toma en cuenta evidencias no solamente textuales, sino también materiales a fin de reconstruir aquellos efectos de sentido que, dentro de una lectura puramente textual, desaparecen y dejan a simple vista un conjunto de versos inconexos y enigmáticos.

El chiste es un tipo de práctica cotidiana que poco tiene que ver con el aura canónica que $R d A$ ha obtenido como consecuencia del lugar que ocupa en las antologías de poesía medieval castellana. Pero ello no tiene por qué escandalizarnos, ya que el hecho artístico no debe entenderse necesariamente como experiencia sublime, sobre todo si lo observamos en tanto acto plenamente ejecutado por y para una comunidad, tal como ocurría con la lectura medieval.

John Dagenais ha argumentado en favor de comprender los textos medievales a la luz de la cultura manuscrita. En su análisis del Libro de buen amor, Dagenais sostuvo la tesis de que el corpus de lo que se llama "literatura medieval" no puede ser abarcado por la crítica semiótica que parte de la noción barthesiana de texte. Dagenais afirmó, en cambio, que los textos medievales no podían comprenderse divorciados de las prácticas que incluían procesos de producción, uso, transcripción, glosa y enmienda. Por lo tanto, debíamos ver al manuscrito como un objeto mediador en prácticas simbólicas. Dagenais propuso que:

Nuestra primera pregunta, entonces, no debe apuntar a qué es lo que el texto medieval (es decir el texto autoral reconstruido) significa, sino a cómo es que ese texto cobró existencia y se movió físicamente por el mundo al que pertenecía. Una vez que entendamos esto tal vez podamos empezar a percibir nuevas formas en las que se ha dado la significación, no obstante, a través y en torno al proceso incierto por el cual se crean los textos medievales. Tomaría, entonces, como punto central para el estudio de la literatura medieval el proceso por el cual un libro manuscrito individual y concreto ha cobrado existencia, ha crecido a través de aquellos elementos agregados en la glosa, comentarios y notas al margen irrelevantes, se ha movido a través del espacio y del tiempo, y, en muchos casos, se ha transformado en otro libro manuscrito, individual y concreto ${ }^{5}$.

\footnotetext{
3 "provides a frame that invites critical reflection on communicative processes" (Bauman y Briggs 1990: 60).

4 "Performance-oriented scholars no longer think of performativity primarily as the use of specific features in signaling particular illocutionary effects within a fixed set of conventions and a given social context. Instead, they view it as the interaction of complex and heterogeneous formal patterns in the social construction of reality (Bauman y Briggs 1990: 64-65)". La traducción es mía.

5 "Our first question, then, must not be what the medieval text (that is, the reconstructed authorial work) signifies, but how that text came into being and moved physically through the world which it belonged. Once we understand this, perhaps we can begin to perceive new ways in which signification occurred despite,
} 
De acuerdo con esta perspectiva, un manuscrito no es tanto una fuente de significado autoral, sino un conjunto de evidencias sobre prácticas de escritura y lectura realizadas por las comunidades.

Bajo la luz de esta manera de entender los procesos de producción de la escritura y la lectura, encuentro que el poema que conocemos modernamente como $R d A$ es, para nosotros, la huella visible y tangible de una broma poética transcrita en el siglo XIII con la finalidad de ser disfrutada por un pequeño grupo de lectores, a saber, los sacerdotes aragoneses de la abadía a la cual perteneció el manuscrito.

Como ya he referido, Franchini (2001) fue tal vez el primero en llamar la atención sobre el humor que el poema contiene. Mi propuesta es avanzar un poco más allá en su argumento a fin de empezar a ver el poema como objeto destinado a ejecutar un chiste inteligente y refinado. Tal como lo entiendo, el chiste contiene humor pero no se reduce a él, ya que es un tipo de enunciación (un modo de performance) y no un mero contenido.

Si nos enfocamos en la manera en que los motivos más heterogéneos de la poesía lírica ibérica logran ser reunidos en una pieza poética y si aceptamos las consecuencias del estudio del manuscrito 3576 de la Biblioteca Nacional de Francia realizado por Franchini, es posible inferir al menos dos conclusiones: que el poema fue leído dentro de un circuito pequeño y cerrado y que la coherencia de su sentido se alcanzaba en su ejecución. En ella, las diversas piezas, en principio juntadas aparentemente de manera caprichosa, adquirían consistencia en tanto elementos destinados a perpetrar una broma.

La aproximación crítica que propongo no pretende cuestionar o siquiera mermar la riqueza simbólica del poema tal como ha sido dilucidada, por ejemplo, en las críticas de Leo Spitzer (1950) y Alfred Jacob (1952), aún vigentes para la discusión. Por el contrario, observar el poema como instrumento para plasmar un chiste permite considerar de qué manera es la huella de una acción simbólica sumamente compleja que afirma la identidad masculina de los clérigos que lo leían, una identidad que estaba en cuestión para los sacerdotes que vivieron las circunstancias históricas y geográficas del Aragón rural de mediados del siglo XIII.

Si estoy en lo correcto, la finalidad del poema era demostrar habilidades eróticas y poéticas con el propósito de burlarse de los caballeros que en las últimas décadas se habían posesionado de un lugar tradicionalmente asignado a los clérigos letrados. Como se sabe, aquellos caballeros arrogantes habían construido una complicada y autoindulgente poética conocida por los lectores modernos como "amor cortés". Frente a ello, la $R d A$ sería una especie de respuesta y desafío bajo la forma de una venganza que imaginariamente permite recuperar el privilegio erótico del clérigo. $R d A$ debería, por lo tanto, ser entendida como una reapropiación de motivos literarios en respuesta a la acumulación de "capital simbólico" a manos de los poetas de la nobleza6.

\footnotetext{
through and around the uncertain process by which medieval manuscript texts were created. I would take as a focal point for the study of medieval literature, then, the process by which an individual, concrete manuscript book came into being, grew through the accretions of the gloss, commentary, and irrelevant marginal jottings, moved through the space and time, and was, in many cases, transformed into another individual, concrete, manuscript book" (Dagenais 1994: 18). La traducción es mía.

${ }^{6}$ Pierre Bourdieu define al capital simbólico como "capital negado, reconocido como legítimo, es decir, desconocido como capital [...] el cual, junto con el capital religioso [...] es quizás la única forma posible de acumulación cuando el capital económico no es reconocido". ["denied capital, recognized as legitimate,
} 
Este procedimiento simbólico puede ser observado como un asedio a un territorio lingüístico que entonces, ya por excelencia, pertenecía a los nobles. Como hombres marginados de las modas y de los beneficios de las cortes, los lectores, a través de la ejecución de este poema podían restituir sus poderes y sus privilegios como sujetos masculinos y letrados. En consecuencia, su eficacia se derivaba de su capacidad de dibujar una marcada frontera entre el poeta noble aficionado y el auténtico y hábil, aquel que poseía enteramente la ciencia del amor y que sabía hablar su lenguaje con fluidez y belleza.

Para fundamentar mis argumentos, debo revisar algunas de las observaciones al manuscrito latino 3576 de la Biblioteca Nacional de Francia propuestas por Franchini (1993). Él sostiene, contrariamente a la información ofrecida por el catálogo de la BNF, que se trata de "un solo manuscrito dividido en tres segmentos textuales" (Franchini 1993: 11). Afirma, además, que el libro debe haber sido manufacturado entre finales del siglo XII y comienzos del siglo XIII y que fue vuelto a encuadernar en el siglo XVIII. Los textos para los cuales este libro fue fabricado, a saber, los "sermones dominicales et sanctorales" fueron transcritos por escribas franceses que dejaron un espacio en blanco "probablemente con la intención de marcar una separación y facilitar así el manejo del manuscrito, ya que carecía de índice y foliación” (Franchini 1993: 15).

En nuestros días, este códice es célebre por el poema transcrito en aquellas páginas en blanco. Al igual que Los diez mandamientos que se encuentran en el mismo volumen, $R d A$ es un agregado aragonés posterior. Dichos agregados muestran a clérigos con conocimientos limitados del latín e interesados en presentarse como capaces de dominar el clima a través de la oración. Se trata, pues, de sacerdotes poco instruidos que trabajaban en un contexto rural.

El siguiente aspecto del manuscrito que me interesa destacar es que este ejemplar pertenece a una familia de libros dedicados a reproducir las homilías escritas por Abbo Sangermanensis, también conocido como Abbo de Saint-German-de Prés. El prólogo de estas homilías "deja bien en claro que no introduce ningún texto culto ni tampoco monástico, sino un homiliario confeccionado de forma inteligible y destinado al uso del clero inferior que necesitaba una exégesis sencilla de los evangelios para la predicación ante los creyentes" (Franchini 1993: 29). Sumando la información lingüística (la presencia categórica del dialecto castellano-aragonés) así como la información del explicit ("Lupus me fecit de Moros"), Franchini infiere que el manuscrito debió de haber sido destinado a "la zona fronteriza entre Aragón y las tierras castellanas de Medinaceli y Soria" (Franchini 1993: 240). Con toda esta información reunida, concluye que el lector de este poema: "no sería el público elitista de la corte, acostumbrado al gallego-portugués o provenzal, sino un público más amplio y más o menos popular a pesar de la evidente cultura de su autor" (Franchini 1993: 240).

Es claro, en consecuencia, que los lectores de este poema deben haber vivido fuera de la corte; a pesar de ello, el texto es una exhibición del manejo no sólo de la poética goliarda (observable en la "conflictio" que constituye la parte conocida como los Denuestos), sino también la cortesana (la "cántiga de amigo" y la "cántiga de amor").

that is, misrecognized as capital [...] which, along with religious capital [...] is perhaps the only possible form of accumulation when economic capital is not recognized" (118)]. La traducción es mía. 
Aquí surge la cuestión acerca de qué quiere decir Franchini por "un público más amplio".

Hasta donde se sabe, contamos con un solo testimonio de este poema. La ausencia de otras versiones pone en cuestión su popularidad. Pero, más importante que ello, resulta ser su ubicación material, pues finalmente, no hay que desdeñar el hecho de que se trata de un poema oculto en medio de textos destinados a la práctica religiosa.

Es notorio que este poema se estructura sobre la base de la oposición entre los nobles y los clérigos. En efecto, las ventajas amatorias del clérigo letrado sobre el militar son señaladas tres veces en el poema entre los versos 5 y 9:

$$
\begin{aligned}
& \text { Vn escolar la Rimo } \\
& \text { que sie[m]pre duenas amo. } \\
& \text { Mas ssie[m]pre ovo tryança } \\
& \text { en Alemania y en Fra[n]cia } \\
& \text { moró mucho en Lombardia } \\
& \text { por aprender cortesia. }
\end{aligned}
$$

Entre los versos 80 y 85 :

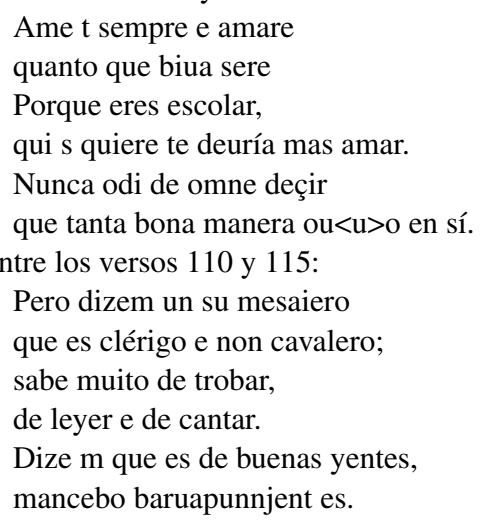

Como puede verse, la oposición entre el "clérigo" y el "cavalero" está bastante marcada y constituye la diferencia que con mayor énfasis se quiere señalar. Al respecto, Franchini reconoce "la casi obsesiva insistencia tanto directa como indirecta, en su refinamiento y su distanciamiento frente a los otros estamentos de la sociedad altomedieval, a saber, los caballeros y los villanos, constituyan un hilo rojo que se extiende a lo largo de toda la primera parte de Razón de amor a modo de leitmotiv". (Franchini 1993: 63). Todo indica, pues, que los destinatarios de $R d A$ eran lectores familiarizados tanto con los modos populares como con los modos poéticos prestigiosos.

En consecuencia, buena parte de la eficacia del poema debió haber residido en el entendimiento de las referencias a los géneros cortesanos y goliárdicos y a los motivos alegóricos, que procedían de una tradición erudita. Ahora bien, una ruptura adquiere sentido en tanto que conocemos los modelos que son violentados; por lo tanto, es perfectamente posible concluir que el poema fue construido para quienes podían entender este juego de ruptura. ¿Quiénes serían esas personas hacia mediados del siglo XIII en Aragón? Probablemente, muy pocas.

La preocupación misma por disminuir el poder erótico de los nobles no pudo haber sido una preocupación muy extendida. Jean Markale sostiene que el amor 
cortés "sólo afecta a una ínfima minoría de gente, siempre en la alta sociedad" y que "el conjunto de la población, sin distinción de clases, no se ve en absoluto afectado por esta nueva 'moda'” (Markale 1998: 11). Si Markale está en lo correcto, es poco probable que $R d A$ haya sido un poema "popular" en cualquiera de los dos sentidos de la palabra: ni debido a su fama ni debido al uso de tradiciones populares. La fuente manuscrita ofrece, desde mi punto de vista, suficiente información para responder a esta pregunta; de hecho, los asuntos tratados parecen más bien relacionados con la represión a los clérigos peninsulares durante el siglo XIII, un asunto al cual el mismo Franchini (2001) le dedica varias páginas.

De acuerdo con Markale, el amor cortés era una práctica elitista y aristocrática que resultó de una alianza del amor "con la propia acción guerrera" (Markale 1998: 29). Esta relación entre amor y guerra es un motivo central para la construcción de la aristocracia del siglo XIII. Por su parte, Frede Jensen señala que "dentro del marco de los ideales del amor cortesano de la época, era de esperarse que un noble poseyera varias cualidades, entre ellas la habilidad de cultivar el arte de trovar, el saber alegre de los poetas provenzales" (Jensen 1978:24) ${ }^{7}$. El trovador era típicamente un noble, aunque algunos burgueses ricos podían alcanzar dicho estatus debido a su independencia económica y a la reconocida excelencia de su arte.

Aunque se encuentra fuertemente asociado a la nobleza y la clase militar, Markale admite que los fundamentos del amor cortés procedían de la actividad intelectual de los monasterios, puesto que tal moda tuvo sus fuentes en la filosofía y la teología. Markale sostiene que "pasado el Año Mil, los artesanos de la cultura no forjarán ya sus armas a la sombra de las catedrales, sino de los monasterios" (Markale 1978: 14) y que "el bajo clero de la campiña, mantenido en la ignorancia o surgido de la espontaneidad popular, no desempeña papel alguno, salvo el de transmisor de la voluntad del alto clero" (Markale 1978: 15).

La moda del amor cortés resulta siendo, entonces, la apropiación por parte de la clase noble y militar de una sabiduría y un arte forjado por los clérigos. Esta apropiación puede ser juzgada como una clara evidencia de que los religiosos habían perdido su prestigio y el monopolio de las letras a favor de una clase ahora orgullosa de poseer la ciencia del amor y la poesía. Como reacción, $R d A$ juega libremente con las reglas de la poesía de los trovadores, no solamente porque combina géneros sino porque sitúa al clérigo como agente del amor erótico. El hecho de que la voz no proceda de un "cavalero" sino de un "escolar" es una evidencia bastante fuerte para apoyar esta argumentación.

En la poética cortesana, el amante es un "cavalero" que estructura su relación con la amada siguiendo la retórica de las relaciones feudales, pero también de la guerra: por un lado, el amante es conquistado por la dama, por otro, el amante asedia el corazón de la mujer. De acuerdo con John Jay Perry, el modelo del amor como guerra proviene de Ovidio, en cuya obra "el amor es una especie de guerra y cada amante es un soldado. El Cupido es el generalísimo" (Perry 1960: 5) ${ }^{8}$. Es perfectamente comprensible,

\footnotetext{
7 "[w]ithin the framework of the courtly ideals of the time, a nobleman was expected to possess a number of qualities, among them the ability of cultivate the arte de trovar, the gay saber of the Proveçal poets" (Jensen 1978: 24). La traducción es mía.

8 "love is a kind of warfare, and every lover is a soldier. Cupid is the generalissimo" (Perry 1960: 5). La traducción es mía.
} 
en consecuencia, que, con la finalidad de estructurar su prestigio social, los poetas cortesanos hayan tomado a Ovidio como su más notorio antecedente.

Pero en $R d A$, la razón por la cual el mancebo debería ser amado por la dama es su educación letrada, no sus habilidades militares. A diferencia de la tradición cortesana, en $R d A$ las metáforas bélicas son dejadas explícitamente (y no solo implícitamente) de lado. En el poema, es el "escolar" y no el "cavalero" quien tiene experiencia en el arte del amor, puesto que el amor es un conocimiento que se adquiere en los viajes y en las lecturas. No es difícil, entonces, leer $R d A$ como un poema basado en la diferenciación entre el sujeto masculino letrado y el sujeto masculino militar quien, según la voz poética, trató sin éxito de expropiar las cualidades del primero.

Por cierto, la sexualidad de los clérigos era problemática debido a la conocida disputa por el concubinato. Peter Linehan explica que el clero español "sobrevivió [...] y neutralizó las fulminaciones del Cuarto Concejo Luterano", , el cual, como sabemos, trató de acabar con las relaciones estables de los curas con sus concubinas (2). A pesar de los muchos intentos, Roma no pudo imponer sus normas y, por el contrario, la resistencia entre los clérigos se avivó. Como lo señala Linehan "el combinado intento del Obispo Gonzalo y el Arzobispo Martin de Toledo de separar el clero de sus mujeres produjo no una reforma de la moral clerical sino una generalizada revolución clerical" (Lineham 1971 2-3) ${ }^{10}$.

Así, pues, hay fuertes motivos para concluir que $R d A$ es evidencia de una reacción, dentro de un entorno microsocial, contra el impacto producido por las presiones del entorno macrosocial. Creo que el poema puede entenderse como una manifestación de orgullo por parte de un grupo de sacerdotes rurales, como una compensación simbólica en clave humorística frente a su condición social y sexual minusvalorada.

Si RdA es una broma, ¿este hecho cuestiona su lugar en la tradición castellana? Antwerp señaló que el debate respecto de la unidad del poema "ha tenido al menos un infortunado resultado: la importancia de Razón de Amor como la primera manifestación de la lirica castellana refinada se ha pasado muy por alto" (Antwerp 1978: 2) ${ }^{11}$. Pero Antwerp, a pesar de su detallado examen de las fuentes "cultas" y "populares", no ofrece ningún vínculo convincente entre el poema y la tradición castellana que ulteriormente se consolidará a través de los cancioneros. En efecto, sin la construcción de las antologías, no es posible hablar propiamente de tradición literaria, ya que ella se elabora mediante trabajos textuales normalmente relacionados con el poder. Como sostuvo Raymond Williams, la tradición "es una versión del pasado que trata de conectar y ratificar el presente. Lo que ofrece en la práctica es un sentido de continuidad predispuesta [...] Es también un proceso vulnerable en todo momento, ya que en la práctica tiene que descartar áreas completas de significancia o bien reinterpretarlas

\footnotetext{
9 "survived [...] and neutralized the fulminations of the Fourth Lateran Council". La traducción es mía.

10 "the combined attempt of Bishop Gonzalo and Archibishop Martin of Toledo to separate the clergy from their women produced not a reformation of clerical morals but widespread clerical revolt" (Linehan 1971 2-3). La traducción es mía.

11 "has had at least one unfortunate result: The importance of Razón de Amor as the first manifestation of the cultured Castilian lyric has been largely overlooked" (Antwerp 1978: 2). La traducción es mía.
} 
o diluirlas, o convertirlas en formas que sustenten o que al menos no contradigan los elementos realmente importantes de la hegemonía vigente" (Williams 1997: 116) ${ }^{12}$.

No se puede hablar de tradición fuera de los constructos simbólicos edificados por las comunidades y la hegemonía. Por tanto, aquello que queramos decir por "lírica castellana" es finalmente un corpus incoherente forzado a ser coherente. De modo que una mirada crítica sobre esa historia nos debería llevar a admitir que, en no pocos casos, algunos textos que muestran cualidades literarias sobresalientes no tuvieron en su origen un aura de sacralidad ni canonicidad que se le haya podido conceder posteriormente y que, más bien, ésta se obtiene mediante su inserción en las antologías que crean y recrean la tradición. Pienso que $R d A$ es el caso ostensible de cómo un texto marginal ha podido convertirse, gracias a operaciones institucionales, en un objeto central en el canon literario, un hecho innegablemente efectuado a posteriori y que oscurece la circunstancia más bien modesta de su origen. Observar esto no significa, en absoluto, discutir el cautivante efecto de belleza que produce entre los lectores contemporáneos.

\section{OBRAS CITADAS}

Antwerp, Margaret van. 1978. "Razón de amor and the Popular Tradition". Romance Philology 32: 1-17.

Azuela, María Cristina. 1993. "La ambigüedad en la Razón de Amor" Nueva Revista de Filología Hispánica 41.1: 201-14.

Bauman, Richard y Charles L. Briggs. 1990. "Poetics and performances as critical perspectives on language and social life". Annual Review of Anthropology 19: 59-88.

Bourdieu, Pierre. 1980. The Logic of Practice. Trad. Richard Nice. Stanford, CA: Stanford UP.

Cárdenas, Daniel N. 1968. "Nueva luz sobre Razón de amor y desnuestos del agua y del vino". Revista Hispánica Moderna 34: 227-41.

Dagenais, John. 1994. The ethics of reading in manuscript culture: glossing the Libro de buen amor. Princeton, N.J.: Princeton UP.

Franchini, Enzo. 1993. El manuscrito, la lengua y el ser literario de la Razón de amor. Madrid: Consejo Superior de Investigaciones Científicas.

Franchini, Enzo. 2001. Los debates literarios en la Edad Media. Madrid: Laberinto.

Jacob, Alfred. 1952. "The Razón de amor as Christian Symbolism". Hispanic Review 20.4: 282-301.

Jensen, Frede. 1978. The Earliest Portuguese Lyrics. Odense: Odense UP.

Linehan. 1971. The Spanish Church and the Papacy in the Thirteenth Century. Cambridge: Cambridge UP.

Markale, Jean. 1998. El amor cortés o la pareja infernal. Palma de Mallorca: Olañeta.

Menéndez Pidal, Ramón. 1976. "Razón de amor con los denuestos del agua y del vino". Textos medievales españoles. Madrid: Espasa Calpe. 109-17.

\footnotetext{
12 "is a version of the past which is intended to connect and ratify the present. What it offers in practice is a sense of predisposed continuity [...] It is also at any time a vulnerable process, since it has in practice to discard whole areas of significance, or reinterpret or dilute them, or convert them into forms which support or at least do not contradict the really important elements of the current hegemony" (Williams 1997: 116). La traducción es mía.
} 
Michaelis de Vasconcelos, Carolina. 1902. "Observações sobre alguns textos lyricos da antiga poesia peninsular. I: O romance de Lope de Moros”. Revista Lusitana 7: 1-32.

Perry, John Jay. 1960. "Prologue". Capellanus, Andreas. The Art of Courtly Love. Ed. John Jay Perry. New York: Columbia UP.

Peter Linehan. 1971. The Spanish Church and the Papacy in the Thirteenth Century. Cambridge: Cambridge UP.

Spitzer, Leo. 1950. "Razón de amor". Romania 71: 145-65.

Tudorica Impey, Olga. 1979. "La estructura unitaria de Razón de amor". Journal of Hispanic Philology 4: 1-24.

Williams, Raymond. 1997. Marxism and Literature. Oxford: Oxford UP. 